\title{
Gentamicin Induced Nephrotoxicity in Long Evans Rat - An Experimental Study
}

\author{
Rama Saha ${ }^{1}$, SAR Choudhury ${ }^{2}$
}

\begin{abstract}
:
Context: Gentamicin is an antibiotic used in gram-negative infection. It is an nephrotoxic agent. Proximal tubular epithelial cells are selectively sensitive to gentamicin.

Objective: To observe the toxic effect of gentamicin on epithelial cells of proximal convoluted tubule in Long Evans rats.
\end{abstract}

Study design: An experimental study.

Plan and period of study: The study was carried out in the Department of Pharmacology of IPGMR Dhaka during the period of 1995 to 1996.

Materials and methods: Eighteen mature long Evans rats were divided into three groups $A, B \& C$. The rats of group $A$ were treated with vehicle and group $B$ and $C$ were treated with gentamicin $50 \mathrm{gm}$ and $100 \mathrm{gm}$ respectively. Blood urea and serum creatinine were measured and microscopic damaged cells were counted.

Result: There was significant increase in serum creatinin and blood urea in gentamicin treated groups. Microscopic examination of kidney showed necrosis of proximal tubular cells.

Conclusion: It can be concluded from this study that gentamicin has toxic effects on renal tubule.

Key words: Gentamicin.

Introduction:

Kidney is especially a susceptible organ to toxic injuries rendered by drugs and toxin, because of high blood supply ${ }^{1}$. The commonest cause of acute renal failure is tubular necrosis.

Gentamicin is an amino glycoside an antibiotic which is commonly used in gram-negative infection. Gentamicin has been reported to cause nephrotoxicity in experimental animal ${ }^{2,3,4}$. It has been reported a patient with normal blood urea nitrogen (BUN) and on urine showed severe renal insufficiency while on usual doses, $2 \mathrm{mg} / \mathrm{kg}$ daily of gentamicin. Therefore, it is assumed that gentamicin therapy may produce nephrotoxicity even in therapeutic doses. Therefore the present study was undertaken to compare the nephrotoxicity in rats with different doses of gentamicin. Renal failure is a

1. Assistant Professor (c.c.), Dept. of Pharmacology, Shaheed Suhrawardy Medical College, Dhaka

2. Former Chairman, Dept. of Pharmacology, BSMMU, Dhaka Correspondence: Dr. Rama Saha continuing challenge with consequence of high mortality and morbidity in our country. The experiment was carried out to produce parenchymal damage of kidney.

Materials and Method:

Eighteen healthy rats were randomly divided into three groups. The animal of group A received normal saline in a dose of $0.75 \mathrm{ml}$. Rats of group $B$ received injection gentamicin in a dose of $50 \mathrm{mg} /$ day and group $\mathrm{C}$ received $100 \mathrm{mg} /$ day. The vehicle and gentamicin injection were administered subcutaneously once daily for consecutive 8 days. All the rats of all groups were sacrificed on 9th day under anesthesia. Their blood samples were collected in test tubes. After collection of blood both kidney were taken out, placed in formalin for histopathology.

The drugs and sacrifice schedule was shown in Table I. 
Table I

Drugs and Sacrifice schedule for experiment

\begin{tabular}{lccccc}
\hline Group & Number $(\mathrm{n})$ & Drugs & Dose & Duration of treatment (day) & Day of sacrifice \\
\hline Group-A & 6 & Normal saline & $0.75 \mathrm{ml}$ & 8 & $9^{\text {th }}$ \\
Group-B & 6 & Gentamicin & $50 \mathrm{mg} /$ day & 8 & $9^{\text {th }}$ \\
Group-C & 6 & Gentamicin & $100 \mathrm{mg} /$ day & 8 & $9^{\text {th }}$ \\
\hline
\end{tabular}

Serum creatinine, blood urea and histopathological parameters were determined and all the results were expressed as mean $\pm \mathrm{SD}$, significance of difference between groups were done by the unpaired student's't' test.

\section{Result:}

The mean ( \pm SEM) serum creatinine level in group $A$ (vehicle) was $1.30 \pm 0.25$ and group $B$ \& $C$ which were gentamicin treated were $3.87 \pm 0.50$ and $3.18 \pm 0.21$ respectively. The mean $[ \pm S D]$ blood urea level of above mentioned three groups of rats were $49.55 \pm 5.75 \mathrm{mg} / \mathrm{dl}, 131.00 \pm 9.55 \mathrm{mg} / \mathrm{dl}$ and $127.66 \pm 13.88 \mathrm{mg} / \mathrm{dl}$ respectively.
The increase in serum creatinine and blood urea in gentamicin treated groups compared to that of control group were statiscally highly significant $(p<0.01)$.

Histopathological examination of kidney showed no necrosis in the proximal tubular cells in the control group. But marked necrosis was found in the gentamicin treated group. The mean number of necrosed proximal convoluted tubules in gentamicin treated rats at a dose of $50 \mathrm{mg} / \mathrm{kg} /$ day and $100 \mathrm{mg} /$ $\mathrm{kg} /$ day were $13.33 \pm 0.25$ and $17.00 \pm 0.50$ respectively. The results were shown in Table II.

Table-II

Serum creatinine, blood urea and necrosed tubular cells in rats included in the study

\begin{tabular}{lccc}
\hline Group of Rats & $\begin{array}{c}\text { Serum creatinine } \\
(\mathrm{mg} / \mathrm{dl})\end{array}$ & $\begin{array}{c}\text { Blood urea } \\
(\mathrm{mg} / \mathrm{dl})\end{array}$ & $\begin{array}{c}\text { No. of necrosed cells in Proximal convoluted } \\
\text { tubules per high power field }(\mathrm{X} 100)\end{array}$ \\
\hline A (Control) & $1.30 \pm 0.50$ & $49.55 \pm 5.75$ & 0 \\
B (Gentamicin treated) & $3.87 \pm 0.50$ & $131.00 \pm 9.55$ & $13.33 \pm 0.25$ \\
C (Gentamicin treated) & $3.18 \pm 0.21$ & $127.66 \pm 13.88$ & $17.00 \pm 0.50$ \\
\hline
\end{tabular}

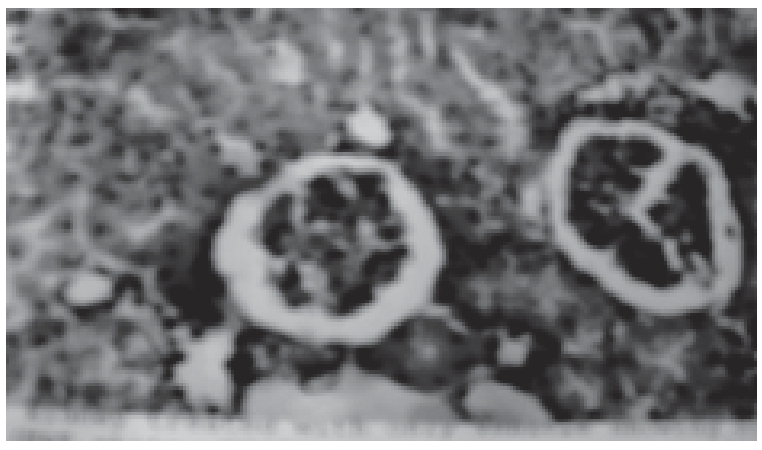

Fig.-1: A high power (X10X10) photomicrograph showing normal structure of kidney section of rats (control group).

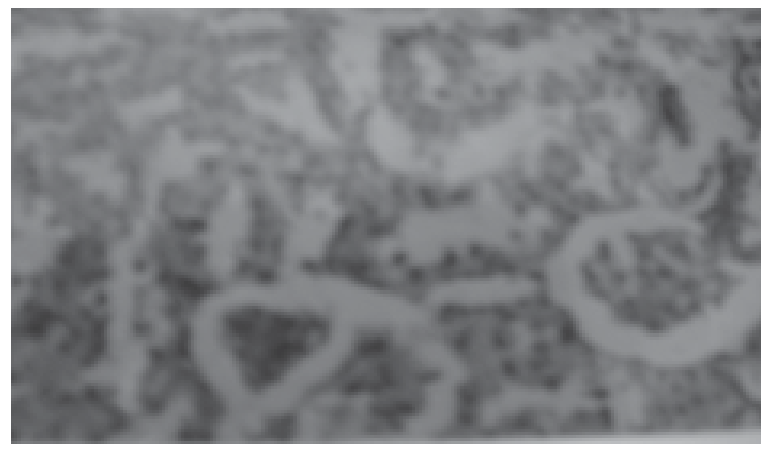

Fig.-2: A high power (X100) photomicrograph showing proximal tubular necrosis of kidney in gentamicin treated rats (50 $\mathrm{mg} /$ day) 


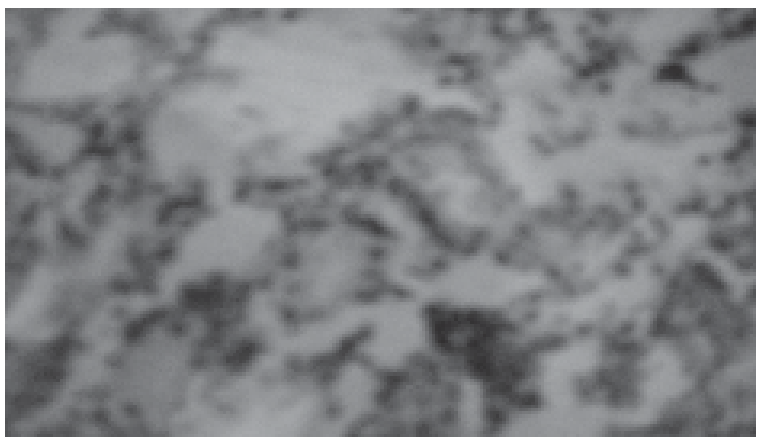

Fig.-3: A high power (X100) photomicrograph showing proximal tubular necrosis of kidney in gentamicin treated rats (100 mg/day)

\section{Discussion:}

It was found that in gentamicin $100 \mathrm{mg} /$ day treated group, 4 out of 6 rats died. This was due to the fact that probably uremia developed with higher doses of gentamicin. This study also suggests that very often side-effects limit the use of many drugs, especially nephrotoxic drug. Gentamicin induced nephrotoxicity is associated with oxidative and nitrosative stress-increased production of reactive oxygen metabolites and lipid per oxidation in kidney. $5,6,7,8$

Results of biochemical histology and general behavior study suggest that gentamicin $50 \mathrm{mg} /$ day $\& 100 \mathrm{mg} /$ day produced nephrotoxicity in rats. These findings closely agree with the findings of Kosek 1974, Cohen 1975, Hassan, Ali and Bashir 1994 $9,10,11$. The specificity of gentamicin for renal toxicity is apparently related to its accumulation in the renal proximal convoluted tubules [50-100 times greater than serum] and lipid per oxidation, giving rise to free radicals which are highly toxic to tissue ${ }^{4}$. These effects further strengthened the occurrence of nephrotoxicity induced by gentamicin in the present study.

However, it has been reported that up to $30 \%$ of patients treated with gentamicin show some signs of nephrotoxicity ${ }^{3}$.

Dose dependent and cumulative nephrotoxicity may be the major toxicity of this agent.

\section{Conclusion:}

These results suggest that nephrotoxicity developed in rats treated with gentamicin, side effect very often limit the use of many drugs especially cytotoxic drugs.

\section{References:}

1. Robbins SL, Cotran RS, Kumar V, editors. Pathologic Basis of Diseases. $5^{\text {th }}$ ed. Philadelphia: W.B. Saunders Company 1994: p. 927-82.

2. Kahn T, Stein, Gentamicin and renal failure \{Letter\}. Lancet 1972; 11.498.

3. Mathew TH. Drug Induced Renal Failure. Med J Aust 1992; 156: 724-8.

4. Walker PD, Shah SV. Evidence suggesting a role for hydroxyl radical in gentamicin-induced acute renal failure in rats. J Clin Invest 1988; 81: 334-41.

5. Williams PD, Hollenerf $\mathrm{GH}$, Bennett DB. Inhibition of Renal Membrane binding and Nephrotoxicity of Aminoglycocides. J Pharmacol Therp 1986; 237: 919-25.

6. Abdel Gayoum AA, Ali BH, Ghawarsha K, Bashir AA. Plasma lipid profile in rats with gentamicin induced Nephrotoxicity. Hum. Exp Toxicol 1993; 12: 371-5.

7. Humes DH, Sastrasinh M, Weinberg JM. Calcium is a Competitive Inhibitor of Gentamicin Renal Membrane Binding Interaction and Dietary Calcium Supplementation Protects Against Gentamicin Induced Nephrotoxicity; J. Clin Invest 1984; 73: 134- 47.

8. Kuhad A, Tirkey N, Pilkhwal S, Chopra K. Renoprotective Effect of Spirulina fusiformis on cisplatin-induced oxidative stress and renal dysfunction in rats. Ren Fail. 2006; 28; 24754.

9. Kosec JC, Mazze RI, Coussins MJ. Nephrotoxicity of Gentamicin. Lab Invest 1974; 30: 48-57.

10. Cohen L, Lapkin R Kaloyanides GJ. Effect of Gentamicin on Renal Function in the rat. J Pharmacol Expl Therapy 1975; 193: 264-73.

11. Ali BH, Bashir AA. Effect of Fish oil Treatment on Gentamicin Induced Nephrotoxicity in Rats. Ann Nutr Metabol 1994; 237: 919-25. 